\title{
Common oxytocin receptor gene polymorphisms and the risk for preterm birth
}

\author{
Lorenz Kuessel $^{\mathrm{a}}$, Christoph Grimm ${ }^{\mathrm{a}}$, Martin Knöfler ${ }^{\mathrm{a}}$, Peter Haslinger ${ }^{\mathrm{a}}$, Heinz Leipold ${ }^{\mathrm{b}}$, \\ Georg Heinze $^{\mathrm{c}}$, Christian Egarter ${ }^{\mathrm{a}}$ and Maximilian Schmid ${ }^{\mathrm{a}, \mathrm{d}, *}$ \\ ${ }^{a}$ Department of Obstetrics and Gynecology, Medical University of Vienna, Vienna, Austria \\ ${ }^{\mathrm{b}}$ Department of Obstetrics and Gynecology, Landeskrankenhaus Klagenfurt, Klagenfurt, Austria \\ ${ }^{\mathrm{c}}$ Center for Medical Statistics, Informatics and Intelligent Systems, Section for Clinical Biometrics, Medical \\ University of Vienna, Vienna, Austria \\ ${ }^{\mathrm{d}}$ Department of Perinatal Medicine, The Royal Women's Hospital, Parkville, Australia
}

\begin{abstract}
Oxytocin is crucially involved in the onset and maintenance of labor. We investigated the association between oxytocin receptor gene polymorphisms and preterm birth. The presence of four common oxytocin receptor gene polymorphisms (rs2254298, rs53576, rs2228485 and rs237911) was evaluated in one hundred women with preterm birth and one hundred healthy women using restriction fragment length polymorphism genotyping. No association was found between the presence of any individual oxytocin receptor gene polymorphism and preterm birth. In haplotype analysis, the haplotype combination of rs2254298 A allele, rs2228485 C allele and rs $237911 \mathrm{G}$ allele was found to be significantly associated with an increased risk of preterm birth (OR $=3.2$ [CI 1.04-9.8], $p=0.043)$. In conclusion our findings suggest that a combination of three oxytocin receptor gene polymorphisms is associated with an increased risk for preterm birth. We propose further studies investigating the role of oxytocin receptor gene polymorphisms and preterm birth.
\end{abstract}

Keywords: Pregnancy, oxytocin receptor, single gene polymorphism, preterm birth

\section{Introduction}

Preterm birth (PTB) is a major health problem. It is the leading cause of perinatal mortality as well as neonatal and long-term morbidity in the industrialized world. In developed countries up to $11 \%$ of children are born preterm and several studies have reported increasing trends in PTB. Despite major progress in perinatal medicine throughout the last decades, PTB still accounts for $70 \%$ of neonatal deaths, up to $75 \%$ of neonatal morbidity and contributes to long-term neurocognitive deficits, pulmonary dysfunction and ophthalmologic disorders [29].

\footnotetext{
*Corresponding author: Maximilian Schmid, Department of Obstetrics and Gynecology, Medical University of Vienna General Hospital, Waehringer Guertel 18-20, 1090 Vienna, Austria. Tel.: +43 1 40400 2822; Fax: +43 140400 2995; E-mail: maximilian.schmid@ meduniwien.ac.at.
}

The mechanisms leading to PTB are complex and still not fully understood. Beside known risk factors, such as demographic characteristics, lifestyle and infection, genetic factors seem to play a crucial role in PTB $[4,10,15,23,27]$. One of the best predictors for preterm delivery is the women's history of a previous PTB [3]. Approximately $20 \%$ of women who deliver preterm subsequently have another PTB with the same partner; changing partners reduces the risk by one third $[2,18]$. Twin studies of pregnancy outcome estimate the heritability of PTB as $17 \%$ to $36 \%$ [4, 26]. Furthermore a large number of potential candidate genes associated with PTB and birth timing have been identified [22]. These studies have traditionally focused on one or a few candidate genes, chosen based on our current understanding of physiology. More recently, genome-wide linkage analyses in families with recurrent PTB and large-scale association studies have revealed further susceptibility genes for PTB [9,21,24]. 
Oxytocin is crucially involved in the onset and maintenance of labor. It is a nine amino acid neuropeptide, which stimulates uterine contractions and lactation and modulates behavior and cognition $[1,8,13,30]$. The human oxytocin receptor (OXTR) is a polypeptide with seven transmembrane domains belonging to the class I G protein-coupled receptor family [8]. Oxytocin activates the OXTR, which is expressed in both the myometrium and the endometrium, as well as in diverse peripheral tissues and the central nervous system [8]. In the myometrium oxytocin activates phospholipase $\mathrm{C}$, which increases the intracellular calcium concentration and thus intensifies uterine contractions. Mediated by activation of the OXTR, oxytocin additionally seems to assist cervical ripening by stimulating the synthesis of prostaglandins in the chorion, decidua, and amnion [7, 12].

The OXTR gene is located on chromosome $3 \mathrm{p} 25.3$. To date, several dozen single nucleotide polymorphisms (SNPs) have been identified within the OXTR gene. These SNPs are indicated in the National Center for Biotechnology Information database (dbSNP). However, little is known about their influence on human physiology. So far OXTR gene polymorphisms have mainly been investigated in a variety of psychiatric disorders and disease [13,19,30]. Additionally, although oxytocin is known to play a crucial in role parturition, until now, to the best of our knowledge, the association between $O X T R$ gene polymorphisms and the risk of PTB has not been investigated. Therefore we evaluated the association of common OXTR single nucleotide polymorphisms (rs2254298, rs53576, rs2228485 and rs237911) and PTB.

\section{Materials and methods}

\subsection{Patients}

In the present retrospective case-control study 200 women with singleton pregnancies were included. Blood samples of 100 consecutive unrelated pregnant women who delivered preterm were included from the Biobank for normal and pathological pregnancies of the Department of Obstetrics and Gynecology, Medical University of Vienna General Hospital, Austria. This included women with spontaneous PTB due to preterm labor (29/100) and preterm premature rupture of membranes (PPROM) (71/100) but no cases where preterm delivery was indicated for medical reasons such as preeclampsia or fetal conditions such as intrauterine growth restriction. Furthermore included cases did not demonstrate any known major fetal chromosomal and/or structural anomalies, significant maternal medical illness (e.g. chronic renal failure, congestive heart failure, connective tissue disorders) or other conditions such as polyhydramnios that increase the a priori risk for PTB. Preterm delivery was defined as delivery before 37 completed weeks of gestation. 100 women with at least one uncomplicated full term singleton pregnancy were asked to serve as controls. Gestational age was calculated from the first day of the last menstrual period and was confirmed by first-trimester ultrasound measurement of fetal crown-rump length. Clinical data were obtained from files at the Medical University of Vienna General Hospital. All patients were of Caucasian origin. Written informed consent was obtained from mothers before collection of biological materials. Approval was obtained by the institutional review board of the Medical University of Vienna (Reference EK Nr.385/2004 and EK Nr. 619/2006).

\subsection{Genotyping}

Genomic DNA was isolated from anticoagulated blood by using the QiAmp Blood Midi Kit, as described by the manufacturer (Quiagen, Hilden, Germany), and stored at $-20^{\circ} \mathrm{C}$. The A/G polymorphism (rs2254298) in intron 3, the $\mathrm{A} / \mathrm{G}$ polymorphism (rs53576) in intron 3 , the $\mathrm{C} / \mathrm{T}$ polymorphism (rs2228485) in exon 3 (amino acid change: $\mathrm{N} 57 \mathrm{~N}$ ) and the A/G polymorphism (rs237911) in the 5'UTR of the OXTR gene were genotyped by using Restriction Fragment Length Polymorphisms.

The reaction was performed in a volume of $25 \mu \mathrm{l}$, consisting of $12.5 \mu \mathrm{lumpStart}{ }^{\mathrm{TM}}$ REDTaq $^{\circledR}$ ReadyMix $^{\mathrm{TM}}$ PCR-Reaction Mix (Sigma, USA) and $40 \mathrm{ng}$ of genomic DNA. The concentration of each primer was $20 \mathrm{pmol} / \mu \mathrm{l}$. Cycle conditions were $95^{\circ} \mathrm{C}$ for 5 minutes; 32 cycles at $95^{\circ} \mathrm{C}$ for 30 seconds, $60^{\circ} \mathrm{C}$ for 40 seconds, $72^{\circ} \mathrm{C}$ for 40 seconds, and $72^{\circ} \mathrm{C}$ for 7 minutes (rs2254298); 5 minutes $95^{\circ} \mathrm{C} ; 32$ cycles at $95^{\circ}$ for 30 seconds, $58^{\circ} \mathrm{C}$ for 40 seconds, $72^{\circ} \mathrm{C}$ for 40 seconds, and $72^{\circ} \mathrm{C}$ for 7 minutes (rs53576); 5 minutes $95^{\circ} \mathrm{C} ; 31$ cycles at $95^{\circ} \mathrm{C}$ for 30 seconds, $65^{\circ} \mathrm{C}$ for 40 seconds, $72^{\circ} \mathrm{C}$ for 40 seconds and finally 7 minutes at $72^{\circ} \mathrm{C}$ (rs2258485) and 5 minutes $95^{\circ} \mathrm{C} ; 32$ cycles at $95^{\circ} \mathrm{C}$ for 30 seconds, $63^{\circ} \mathrm{C}$ for 40 seconds, $72^{\circ} \mathrm{C}$ for 40 seconds and 7 minutes at $72^{\circ} \mathrm{C}$ (rs237911). A $15 \mu \mathrm{l}$ of the PCR-product was digested over night using $5 \mathrm{U}$ of restriction enzyme. Fragments were separated by electrophoresis on an ethidium bromide-stained agarose gel (2\%) and analyzed under UV light. 


\begin{tabular}{|c|c|c|c|c|}
\hline \multirow{3}{*}{ rs2254298 } & Primer 5'-3' & Product & RFLP & Allele (bp) \\
\hline & TGAAAGCAGAGGTTGTGTGGACAGG & $307 \mathrm{bp}$ & BsrI & A $9 / 163 / 34 / 101$ G $9 / 163 / 135$ \\
\hline & AACGCCCACCCCAGTTTCTTC & & & \\
\hline \multirow[t]{2}{*}{ rs53576 } & GCCCACCATGCTCTCCACATC & $340 \mathrm{bp}$ & BamH I & A $120 / 220$ G 340 \\
\hline & GCTGGACTCAGGAGGAATAGGGAC & & & \\
\hline \multirow[t]{2}{*}{ rs2228485 } & CTCATTTGCAGTGGCTCAGA & $340 \mathrm{bp}$ & BsmI & C 340 T $110 / 230$ \\
\hline & ATGAGCAGCAGCAGGTAGGT & & & \\
\hline rs237911 & CCCTTTACGGCTTGGCG & $300 \mathrm{bp}$ & AvaII & A 300 G 100/200 \\
\hline
\end{tabular}

Table 1

Patients' characteristics

\begin{tabular}{lcccc}
\hline Characteristics & Women with preterm birth & full term pregnancy & P-value & OR (95\%CI) \\
\hline Total number of patients & 100 & 100 & - & - \\
Maternal age (years) & $28.9(6.4)^{2}$ & $28.9(6.4)^{2}$ & 0.9 & - \\
History of previous preterm birth & 20 & 0 & $<0.0001$ & $2.3(1.9-2.6)$ \\
Gestational age at delivery (weeks) & $29.5(3.3) 2$ & $39.5(1.1) 2$ & $<0.001$ & - \\
Birth weight (grams) & $1356.3(605.0) 2$ & $3379.9(465.7) 2$ & $<0.001$ & - \\
First pregnancy & 32 & 46 & 0.06 & $0.5(0.3-0.9)$ \\
Delivery mode & & & \\
Caesarean section & 84 & 30 & $<.0001$ & $12.3(6.2-24.3)$ \\
Spontaneous delivery & 16 & 70 & 0.06 & $4.8(1.0-23.0)$ \\
Antenatal bacterial vaginosis & 9 & 2 & 0.6 & $3.1(0.3-29.9)$ \\
LLETZ conisation & 3 & 1 & 0.005 & $12.2(1.5-96.7)$ \\
Smoking & 11 & 1 & \\
\hline
\end{tabular}

${ }^{1}$ Odds Ratio (95\% Confidence Interval); ${ }^{2}$ Mean (Standard deviation); ${ }^{3}$ Student's t-test; ${ }^{4}$ Chi-square test.

\subsection{Statistical analysis}

After testing for normality using KolmogorovSmirnov test, values are given as medians (interquartilerange [IQR]) or means (standard deviation [SD]) where appropriate. Hardy-Weinberg Equilibrium was tested by chi square tests comparing expected and observed genotype frequencies. Groups were compared using Student's t-tests and chi-square tests where appropriate. Statistics have been performed accordingly. P-values and OddsRatios (OR) with $95 \%$ Confidence Intervals (95\% CI) were calculated major/major vs. major/minor and minor/minor allele, i.e. major versus presence of at least one minor allele. Haplotype frequencies were estimated by using SAS/Genetics software. A logistic regression model was estimated to assess the combined effect of rs2254298, rs2228485 and rs237911 haplotypes on the risk for PTB. The haplotype rs2254298 G allele - rs2228485 T allele - rs237911 A allele was set as reference haplotype. Haplotypes occurring with a frequency of four percent or less were pooled. P-values $<0.05$ were considered statistically significant. They have not been corrected for multiple testing. Statistical software SPSS for Windows (SPSS 11.0, SPSS Inc., Chicago, IL) and SAS System (Version 9.1 SAS Institute Inc., Cary, NC) were used for statistical analysis. The linkage disequilibrium (LD) plot was generated with Haploview (Version 4.2 Broad Institute, Cambridge, MA).

\section{Results}

Patient characteristics are shown in Table 1. For rs53576, $100 \%$ prevalence of the GG genotype was found in both groups and therefore this gene polymorphism was not included in further statistical analysis. Distributions of the gene polymorphisms rs2254298 $(p=0.9$ and $p=0.5), \operatorname{rs} 2228485$ ( $p=0.8$ and $p=$ $1.0)$ and $\operatorname{rs} 237911$ ( $p=1.0$ and $p=0.9$ ) in women with PTB and controls were in Hardy-Weinberg equilibrium, respectively. A LD blot for cases is shown in Fig. 1. No significant association was found between the investigated OXTR genotypes and PTB in univariate analysis (Table 2). The main risk factors for PTB were history of PTB (OR 6.0[95\% confidence interval (CI) 4.0-9.0]) and smoking (OR 12.2[95\%CI 1.5-96.7]). Other well-known risk factors such as antenatal bacterial vaginosis (OR 4.8[95\%CI 1.0-23.0]) and history of LLETZ (OR 3.1[95\%CI 0.3-29.9]) were not associated with preterm birth in our sample (Table 1). Additionally, haplotype analysis was performed to identify risk combinations of the three OXTR gene polymorphisms and preterm birth. The haplotype combination rs2254298 A allele, rs2228485 C allele, and rs237911 $\mathrm{G}$ allele was found to be significantly associated with an increased risk of preterm birth $(\mathrm{OR}=3.5$ [CI 1.1-11.0], $p=0.03$, Table 3). 
Table 2

Genotype and allele frequencies of $O X T R$ gene polymorphisms in women with preterm birth and women with full term pregnancy

\begin{tabular}{|c|c|c|c|c|}
\hline & Women with preterm birth & Women with full term pregnancy & P-value & OR $(95 \% \mathrm{CI})$ \\
\hline \multicolumn{5}{|c|}{$r s 2254298$} \\
\hline $\mathrm{G} / \mathrm{G}$ & $70(70.0 \%)$ & $82(82.0 \%)$ & $0.07^{1}$ & $2.0(1.0-3.8)^{1}$ \\
\hline G/A & $28(28.0 \%)$ & $15(15.0 \%)$ & & \\
\hline $\mathrm{A} / \mathrm{A}$ & $2(2.0 \%)$ & $3(3.0 \%)$ & & \\
\hline \multicolumn{5}{|l|}{ Alleles } \\
\hline $\mathrm{G}$ & $168(84.0 \%)$ & $179(89.5 \%)$ & 0.1 & $1.6(0.9-2.9)$ \\
\hline A & $32(16.0 \%)$ & $21(10.5 \%)$ & & \\
\hline \multicolumn{5}{|c|}{$r s 2228485$} \\
\hline $\mathrm{T} / \mathrm{T}$ & $54(54.0 \%)$ & $64(64.6 \%)$ & $0.1^{1}$ & $1.6(0.9-2.8)^{1}$ \\
\hline $\mathrm{T} / \mathrm{C}$ & $41(41.0 \%)$ & $31(31.3 \%)$ & & \\
\hline $\mathrm{C} / \mathrm{C}$ & $5(5.0 \%)$ & $4(4.0 \%)$ & & \\
\hline \multicolumn{5}{|l|}{ Alleles } \\
\hline $\mathrm{T}$ & $149(74.5 \%)$ & $159(80.3 \%)$ & 0.2 & $1.4(0.9-2.2)$ \\
\hline $\mathrm{C}$ & $51(25.5 \%)$ & $39(19.7 \%)$ & & \\
\hline \multicolumn{5}{|c|}{ rs 237911} \\
\hline $\mathrm{G} / \mathrm{G}$ & $76(76.0 \%)$ & $79(75.0 \%)$ & $0.7^{1}$ & $1.2(0.6-2.3)^{1}$ \\
\hline $\mathrm{G} / \mathrm{A}$ & $22(22.0 \%)$ & $18(22.0 \%)$ & & \\
\hline $\mathrm{A} / \mathrm{A}$ & $2(2.0 \%)$ & $3(3.0 \%)$ & & \\
\hline \multicolumn{5}{|l|}{ Alleles } \\
\hline G & $174(87.0 \%)$ & $176(88.0 \%)$ & 0.9 & $1.1(0.6-2.0)$ \\
\hline A & $26(13.0 \%)$ & $24(12.0 \%)$ & & \\
\hline
\end{tabular}

${ }^{1}$ P-value and Odds Ratio (95\% Confidence Interval) were calculated major/major vs. major/minor and minor/minor allele.

Table 3

Haplotype analysis of the three OXTR gene polymorphisms in women with full term pregnancy (controls) and women with preterm birth (cases)

\begin{tabular}{|c|c|c|c|c|}
\hline Haplotypes (rs2254298-rs2228485-rs237911) & Cases $(\%)$ & Controls $(\%)$ & P-value & OR $(95 \% \mathrm{CI})$ \\
\hline G-T-G (reference) & 65.7 & 70.8 & & \\
\hline A-C-G & 7.0 & 2.4 & 0.03 & $3.5(1.1-11.0)$ \\
\hline A-T-G & 8.7 & 7.5 & 0.5 & $1.4(0.6-3.3)$ \\
\hline G-C-A & 12.7 & 9.8 & 0.1 & $1.7(0.9-3.5)$ \\
\hline G-C-G & 5.6 & 7.2 & 0.7 & $0.8(0.4-1.9)$ \\
\hline others & 0.3 & 2.3 & 0.2 & $0.1(<0.001-3.2)$ \\
\hline
\end{tabular}

\section{Discussion}

In the present study we evaluated the association between four common OXTR gene polymorphisms and risk of PTB. We were unable to demonstrate an association between any of four common individual OXTR gene polymorphisms and PTB. Nonetheless, the haplotype rs2254298 A allele- rs2228485 C allele- rs237911 $\mathrm{G}$ allele was found to be associated with an increased risk of PTB.

Oxytocin, exerting its effects via the OXTR, plays a crucial role in parturition. Around the onset of labor, uterine sensitivity to oxytocin markedly increases, which is associated with both an upregulation of OXTR mRNA levels and a strong increase in the density of myometrial oxytocin receptors $[6,14]$. Therefore in modern obstetric practice, oxytocin is widely used to induce and augment contractions during labor [28]. Furthermore, associations between several maternal gene polymorphisms, such as tumor necrosis factor, interleukin (IL)-4, IL-1ß receptor antago- nist, matrix metalloproteinase 9, B2-adrenergic receptor, vascular endothelial growth factor and for Factor V Leiden [11] and PTB have been described. Consequently, we speculated that $O X T R$ gene polymorphisms might also play a role in PTB and to the best of our knowledge are the first to have investigated association of OXTR single nucleotide polymorphisms rs2254298, rs53576, rs2228485, rs237911 and PTB.

Despite the crucial role of the OXTR in the onset and maintenance of labor, we were not able to ascertain a role of any individual of the investigated OXTR single nucleotide polymorphisms in PTB. This may partly be due to the fact that despite the fact that these OXTR gene polymorphisms have been investigated in a variety of diseases, their biological effects and exact influence on the oxytocin mediated pathways have not been clarified $[13,19,30]$. Thus, individual polymorphisms may not have any effect and influence on labor at all. Furthermore, the observed genotype distributions vary significantly between populations and thus possibly different causes for PTB. Therefore, we cannot rule out that 


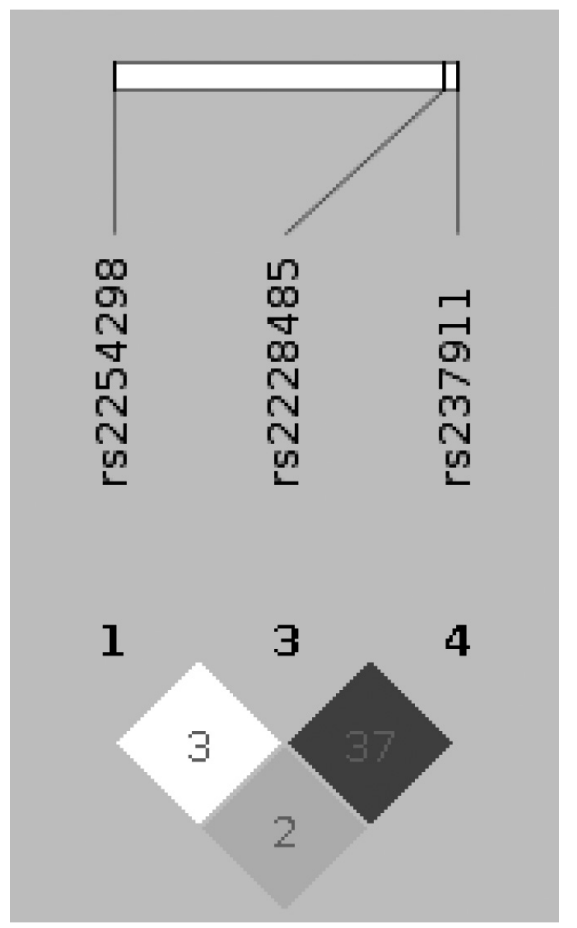

Fig. 1. Linkage disequilibrium (LD) plots of three OXTR gene polymorphisms in women with preterm birth. The names and relative positions of the polymorphisms are shown at the top. Pairwise $D^{\prime} \times$ 100 values are shown in the squares. Darker colors indicate higher LD.

by studying a more homogenous population, such as Caucasian women with preterm labor only, a significant association with individual $O X T R$ gene polymorphisms might be found.

Since presence of any individual OXTR gene polymorphism could not be associated with PTB we further sought to investigate their combined effect [4]. Thus, we performed haplotype analysis to identify possible OXTR risk combinations for an increased risk of PTB. The haplotype combination of rs2254298 A allele, rs2228485 C allele, and rs237911 G allele was significantly associated with an increased risk of preterm birth. This seems interesting, as SNPs rs2254298 and rs2228485 have been previously associated with positive and negative affect [13]. Consequently it has been hypothesized that human affect regulation may be mediated by Oxytocin via its effect on the hypothalamicpituitary-adrenal axis. On a possible role of this pathway in the pathogenesis of PTB can still only be speculated since the underlying biological mechanisms are still not fully understood.

Our study has several limitations. First of all, it was not designed to investigate the association between $O X$ -
$T R$ gene polymorphism and Oxytocin serum levels or OXTR expression. Moreover, the included cases and controls reflect a highly selected group of patients as all have been recruited at a single tertiary care center. However, as expected, we found that maternal smoking and history of PTB were the main risk factors for PTB in cases. This is in accordance with the present literature $[3,5,16,17,20,25]$. Conversely, bacterial vaginosis and LLETZ conisation were not associated with PTB in our study, although they represent established risk factors for PTB. This might be attributed to the limited number of patients included in the present study. Additionally, genome-wide studies are far superior to studies such as ours looking at selected gene polymorphisms to a gain a better etiologic and biologic understanding of the hereditary components of PTB [22]. Recently, genome-wide linkage analyses and association studies performed in Finnish families with recurrent PTB have revealed insulin-like growth factor 1 and follicle hormone simulating hormone receptor genes as susceptibility genes for PTB [9,21]. Furthermore, as only maternal blood samples were available we did not take into account the possible role of fetal genes in our study. A large genetic association study of candidate genes involved in adverse pregnancy outcome has recently accentuated that both maternal and fetal DNA variants are associated with spontaneous preterm delivery [24]. Also, the ideal study genetic study of PTB would take the intricate interactions of environmental factors and genetic predispositions into account. However, given the current methodology and knowledge of biology, the ideal genetic study of PTB may not yet be possible.

To conclude, oxytocin is a crucial factor in parturition and PTB seems to be strongly affected by hereditary factors. To the best of our knowledge, this is the first study to investigate the association between four common OXTR gene polymorphisms and the risk of PTB in Caucasian women. We were not able to ascertain an association between any individual investigated OXTR gene polymorphisms and PTB. However we found that thee haplotype combination of rs2254298 A allele, mutant rs2228485 C allele, and rs237911 G allele was significantly associated with an increased risk of PTB. We propose further studies investigating the role of OXTR gene polymorphisms and PTB.

\section{Acknowledgements}

This study was funded by the Medical Scientific Grant of the Mayor of the City of Vienna. 


\section{References}

[1] M. Akerlund, Vasopressin and oxytocin in normal reproduction and in the pathophysiology of preterm labour and primary dysmenorrhoea. Development of receptor antagonists for therapeutic use in these conditions. Rocz Akad Med Bialymst, (2004). 49. 18-21.

[2] L. S. Bakketeig, H. J. Hoffman, et al., The tendency to repeat gestational age and birth weight in successive births. Am J Obstet Gynecol, (1979). 135. 1086-103.

[3] S. L. Bloom, N. P. Yost, et al., Recurrence of preterm birth in singleton and twin pregnancies. Obstet Gynecol, (2001). 98. 379-85.

[4] B. Clausson, P. Lichtenstein, et al., Genetic influence on birthweight and gestational length determined by studies in offspring of twins. BJOG, (2000). 107. 375-81.

[5] M. S. Esplin, E. O'Brien, et al., Estimating recurrence of spontaneous preterm delivery. Obstet Gynecol, (2008). 112. 516-23.

[6] A. R. Fuchs, M. J. Fields, et al., Oxytocin and the timing of parturition. Influence of oxytocin receptor gene expression, oxytocin secretion, and oxytocin-induced prostaglandin F2 alpha and E2 release. Adv Exp Med Biol, (1995). 395. 405-20.

[7] A. R. Fuchs, F. Fuchs, et al., Oxytocin receptors and human parturition: A dual role for oxytocin in the initiation of labor. Science, (1982). 215. 1396-8.

[8] G. Gimpl and F. Fahrenholz, The oxytocin receptor system: Structure, function, and regulation. Physiol Rev, (2001). 81. 629-83.

[9] R. Haataja, M. K. Karjalainen, et al., Mapping a new spontaneous preterm birth susceptibility gene, IGF1R, using linkage, haplotype sharing, and association analysis. PLoS Genet, (2011). 7. e1001293.

[10] K. Hao, X. Wang, et al., A candidate gene association study on preterm delivery: application of high-throughput genotyping technology and advanced statistical methods. Hum Mol Genet, (2004). 13. 683-91.

[11] C. Hartel, D. Finas, et al., Polymorphisms of genes involved in innate immunity: Association with preterm delivery. Mol Hum Reprod, (2004). 10. 911-5.

[12] M. Johnson, Parturition, in Johnson and Everitt's essential reproduction 2007, Blackwell Publishing Co, pp. 245-254.

[13] Y. Kawamura, X. Liu, et al., The association between oxytocin receptor gene (OXTR) polymorphisms and affective temperaments, as measured by TEMPS-A. J Affect Disord, (2010). 127. 31-7.

[14] T. Kimura, O. Tanizawa, et al., Structure and expression of a human oxytocin receptor. Nature, (1992). 356. 526-9.
[15] Z. A. Kistka, E. A. DeFranco, et al., Heritability of parturition timing: An extended twin design analysis. Am J Obstet Gynecol, (2008). 199. 43 e1-5.

[16] N. B. Kyrklund-Blomberg and S. Cnattingius, Preterm birth and maternal smoking: Risks related to gestational age and onset of delivery. Am J Obstet Gynecol, (1998). 179. 1051-5.

[17] N. B. Kyrklund-Blomberg, F. Granath, et al., Maternal smoking and causes of very preterm birth. Acta Obstet Gynecol Scand, (2005). 84. 572-7.

[18] D. K. Li, Changing paternity and the risk of preterm delivery in the subsequent pregnancy. Epidemiology, (1999). 10. 148-52.

19] M. J. Lucht, S. Barnow, et al., Associations between the oxytocin receptor gene (OXTR) and affect, loneliness and intelligence in normal subjects. Prog Neuropsychopharmacol Biol Psychiatry, (2009). 33. 860-6.

[20] M. B. Meyer and J. A. Tonascia, Maternal smoking, pregnancy complications, and perinatal mortality. Am J Obstet Gynecol, (1977). 128. 494-502.

[21] J. Plunkett, S. Doniger, et al., An evolutionary genomic approach to identify genes involved in human birth timing. PLoS Genet, (2011). 7. e1001365.

[22] J. Plunkett and L. J. Muglia, Genetic contributions to preterm birth: Implications from epidemiological and genetic association studies. Ann Med, (2008). 40. 167-95.

[23] T. F. Porter, A. M. Fraser, et al., The risk of preterm birth across generations. Obstet Gynecol, (1997). 90. 63-7.

[24] R. Romero, D. R. Velez Edwards, et al., Identification of fetal and maternal single nucleotide polymorphisms in candidate genes that predispose to spontaneous preterm labor with intact membranes. Am J Obstet Gynecol, (2010). 202. 431 e1-34.

[25] W. J. Simpson, A preliminary report on cigarette smoking and the incidence of prematurity. Am J Obstet Gynecol, (1957). 73. 807-15.

[26] S. A. Treloar, G. A. Macones, et al., Genetic influences on premature parturition in an Australian twin sample. Twin Res, (2000). 3. 80-2.

[27] K. Ward, V. Argyle, et al., The heritability of preterm delivery. Obstet Gynecol, (2005). 106. 1235-9.

[28] S. Q. Wei, Z. C. Luo, et al., High-dose vs low-dose oxytocin for labor augmentation: A systematic review. Am J Obstet Gynecol, (2010). 203. 296-304.

[29] S. W. Wen, G. Smith, et al., Epidemiology of preterm birth and neonatal outcome. Semin Fetal Neonatal Med, (2004). 9. 429-35.

[30] S. Wu, M. Jia, et al., Positive association of the oxytocin receptor gene (OXTR) with autism in the Chinese Han population. Biol Psychiatry, (2005). 58. 74-7. 


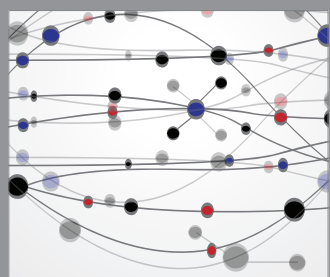

The Scientific World Journal
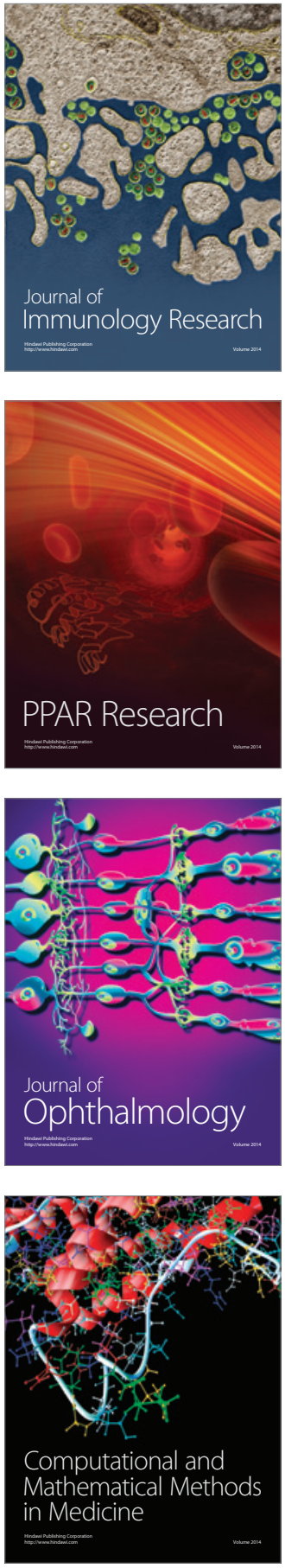

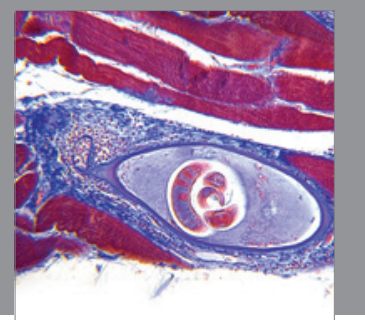

Gastroenterology

Research and Practice
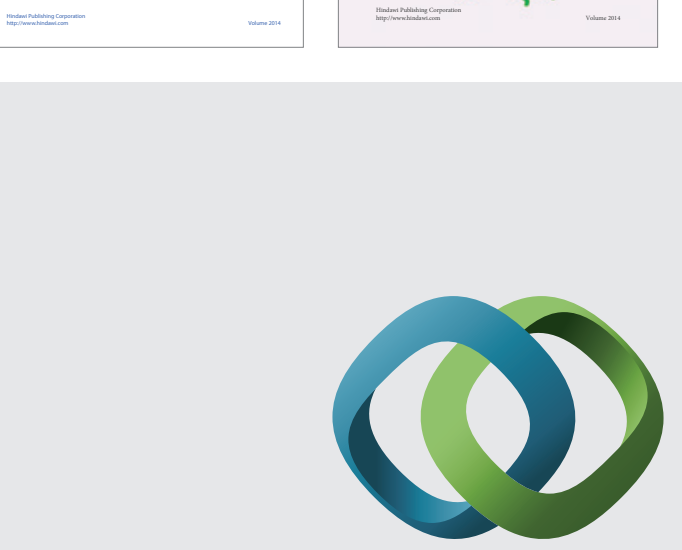

\section{Hindawi}

Submit your manuscripts at

http://www.hindawi.com
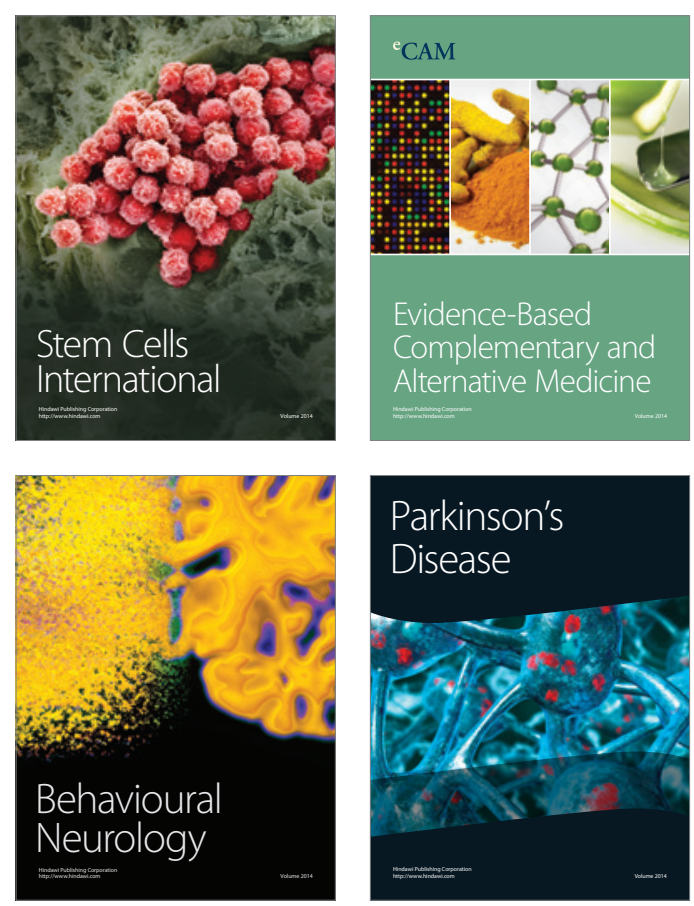

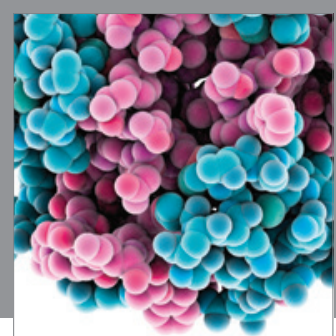

Journal of
Diabetes Research

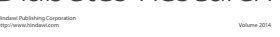

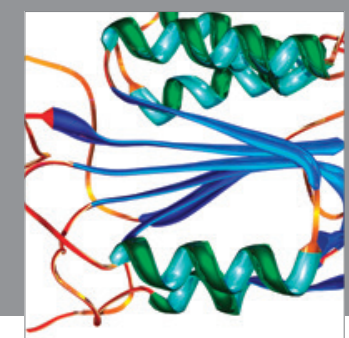

Disease Markers
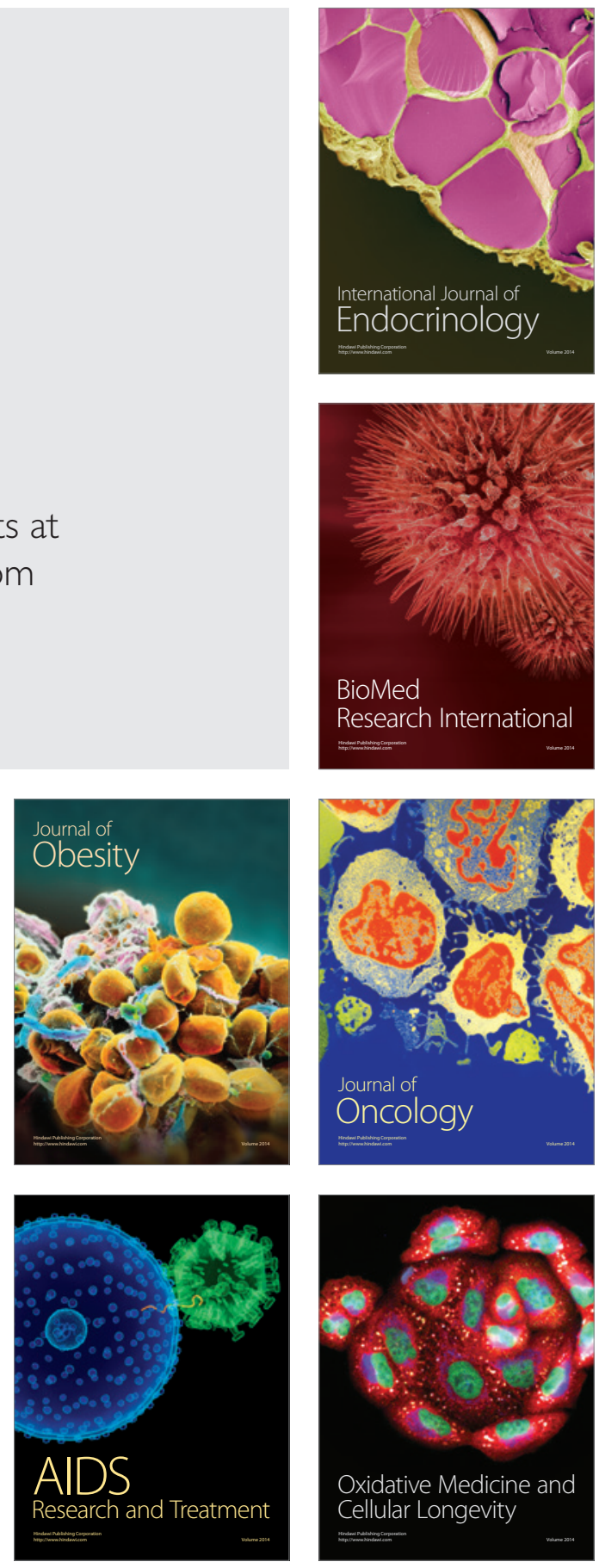